\title{
German syndrome
}

INSERM

\section{Source}

INSERM. (1999). Orphanet: an online rare disease and orphan drug data base. German syndrome. ORPHA:2077

German syndrome is an autosomal recessive arthrogryposis syndrome, described in 5 cases. Three of the four known families with affected children were Ashkenazi Jews. German syndrome is characterized by arthrogryposis, hypotonia-hypokinesia sequence, and lymphedema. Patients present distinct craniofacial appearance (tall forehead and "carp"-shaped mouth, cleft palate), contractures, severe hypotonia manifesting as motor delay, and swallowing difficulties. The disease has a severe morbidity and mortality rate and survivors present a small stature, hypotonia, frequent upper respiratory infections, and psychomotor delay. There have been no further descriptions in the literature since 1987. 